\title{
PENGEMBANGAN MEDIA JARING-JARING BANGUN RUANG DALAM MODEL PEMBELAJARAN ASSURE KELAS V SEMESTER II DI SDN PUCANG SIDOARJO
}

\author{
Eny Wahyudati \\ Guru SDN Pucang III Sidoarjo, \\ Mahasiswa Program Pasca Sarjana Universitas ADI BUANA Surabaya \\ wahyudatieny@gmail.com
}

Media Development Research Jaring-jaring Bangun Ruang with ASSURE Learning Model Class V Semester II SDN Pucang Sidoarjo district motivated by learning according to the observations of researchers are still teachercentered. Task of the teacher explains the subject matter, giving example problems and exercises, while the assignment of students just listen to the teacher's explanations, noting the subject matter and do the exercises. Because of lack of varied learning, then students easily saturated and bored.

The purpose of this development is to produce research of learning nets Media Room Wake up to the steps of learning ASSURE Learning Model is expected to improve the quality of learning. ASSURE Learning Model is done with these steps: Analyse learner, State objectives, Select methods, media, materials, utilize media and materials, Require learner participation, and Evaluate and revise. ASSURE learning activities include: 1) identify and analyze the characteristics of students associated with learning outcomes, 2) formulate and set learning goals, 3) choosing a strategy, choosing technologies and media as well as modify the material, 4) teacher planning to use the technology, media and materials to achieve learning goals, 5) learning requires active mental engagement of students, 6) tested the learning process, assess and revise the material.

After students learn with media Jaring-jaring Bangun Ruang in the ASSURE Learning Model in which students more effective learning activities, students find pleasure in learning and achievement. This is evident with the increase in the acquisition of learning. Increased learning ability is supported by student work in the form of worksheets and observation of student activity sheets. Also from the questionnaire responses of students towards learning it, obtained an average score of 10 item statements given is 88.3 This shows that the response of students towards learning nets to Build Space ASSURE Learning Model can be very positive category. Based on the findings of this study, it is recommended to teachers of mathematics in making learning as follows: (1) makes the ASSURE Learning Model as a liberation $\neg$ lesson worth considering alternatives, (2) assist students in learning through the use of modern media, (3) develop this study that the results of this study is more comprehensive and profound.

Key words: Jaring-jaring Bangun Ruang Media, ASSURE Learning Model 


\section{Penelitian Pengembangan \\ Media Jaring-jaring Bangun Ruang \\ Dalam model pembelajaran ASSURE Kelas V Semester II di SDN Pucang Sidoarjo merupakan penelitian pengembangan media pembelajaran yang menggunakan model pembelajaran beorientasi kelas. Pengembangan bahan ajar meliputi rencana pelaksanaan pembelajaran, lembar kerja siswa dan media pembelajaran. \\ Peraturan Pemerintah No 19}

Tahun 2005 Bab I Ayat 6 tentang Standar Proses Pendidikan adalah Standar Nasional Pendidikan yang berkaitan dengan Pelaksanaan Pembelajaran pada Satuan Pendidikan. Proses pendidikan berfungsi sebagai alat untuk mencapai tujuan pendidikan, yakni kompetensi yang harus dicapai dalam pelaksanaan pembelajaran. Guru sebagai pengelola pembelajaran berperan menciptakan iklim belajar yang memungkinkan siswa dapat belajar secara nyaman dan berhasil maksimal. Berikut disebutkan ciri-ciri guru yang inovatif (Sudrajad. 2010:6); 1) Mengikuti perubahan dan perkembangan zaman, 2) Tidak puas dengan yang ada, 3) Suka dengan hal yang baru, 4) Berbasis mutu, 5) Kreatif dan produktif, 6) Hambatan digunakan sebagai tantangan, 7) Bertanggung jawab dengan tugasnya, 8) Adaptasi tinggi, 9) Mengutamakan ketercapaian tujuan.

$$
\text { Dalam penelitian }
$$

pengembangan ini peneliti (sebagai guru) menyampaikan pengembangan bahan ajar tentang Jaring-jaring Bangun Ruang dengan model pembelajaran yang disebut Model Pembelajaran ASSURE Analize learner (Menganalisis siswa), State objectives (Merumuskan tujuan pembelajaran) Select methods,media,material (Memilih metode,media, dan bahan ajar), Utilize media and materials (Menggunakan media dan bahan ajar), Require learner participation (mengembangkan peran serta siswa), dan Evaluate and revise (Menilai dan memperbaiki). Model pembelajaran ASSURE dipilih karena model pembelajaran ini merupakan model pembelajaran dengan pendekatan yang berorientasi kelas.

Smaldino, James D Russel dan Michael Molenda (2005: 69), mengemukakan sebuah desain sistem pembelajaran yang dikenal dengan ASSURE. Model ini dikembangkan untuk menciptakan aktivitas pembelajaran yang efektif dan efisien, khususnya pada kegiatan pembelajaran yang menggunakan media dan teknologi. Dalam model pembelajaran ASSURE tidak menyebutkan strategi pembelajaran secara eksplisit. Strategi pembelajaran dikembangkan melalui pemilihan dan pemanfaatan metode, media, bahan ajar, dan peran serta siswa dikelas (Salma:47). Model pembelajaran ASSURE lebih memperhatikan karakteristik siswa dan memanfaatkan penggunaan media.

Teknologi juga dapat membantu untuk meningkatkan 
interaksi antar pengajar dan pelajar, dan membuat proses belajar yang berpusat pada pelajar (student oriented). Dengan kata lain, penggunaan media menggunakan audio visual atau komputer media dapat membantu siswa itu memperoleh pembelajaran yang bermanfaat. Guru sebagai pengembang media pembelajaran harus mengetahui perbedaan pendekatanpendekatan dalam belajar agar dapat memilih strategi pembelajaran yang tepat.

Penulis berharap dengan memperkenalkan model pembelajaran ASSURE siswa dapat berfikir lebih efektif, dapat mengembangkan sikap kolaboratif, mampu memahami masalah aktual, mampu membangun sendiri pengetahuannya dengan aktif dan kreatif dalam suasana belajar lebih efektif, menyenangkan, dan bermakna, karena semua siswa ikut aktif dalam kegiatan pembelajaran melalui media yang sesuai. Dengan demikian akan tercapai pemahaman yang optimal.

Tahap pertama dalam perencanaan pembelajaran adalah mengidentifikasi dan menganalisis karakteristik siswa yang diasosiasikan dengan hasil belajar. Informasi tersebut akan membimbing keputusan guru dalam membuat desain pembelajaran.

Langkah berikutnya adalah menetapkan standar dan tujuan pembelajaran sekhusus mungkin. Dalam menentukan pernyataan tujuan,
Smaldini (2007: 256) menganjurkan "Menentukan tujuan dengan menggunakan rumusan ABCD (Audience, Behavioris, Condition, dan Degree)."

Langkah-langkah dalam tahap Select methods,media,material adalah memilih strategi, memilih teknologi dan media serta memodifikasi bahan pelajaran. Guru harus memilih media yang ada disesuaikan dengan tujuan pengajaran. Jika media itu rusak atau kurang sesuai harus diperbaiki terlebih dahulu. Tetapi jika media yang ada tidak sesuai dengan tujuan pengajaran, guru harus membangun/membuat media yang baru disesuaikan dengan judul dan tujuan pengajaran.

Heinich dkk, menyatakan ada tiga hal penting dalam pemilihan metode, bahan dan media yaitu:

1. menentukan metode yang sesuai dengan tugas pembelajaran,

2. memilih media yang sesuai untuk melaksanakan media yang dipilih,

3. memilih dan atau mendesain media yang telah ditentukan.

Langkah Utilize media and materials termasuk perencanaan guru untuk menggunakan teknologi, media dan bahan untuk mencapai tujuan pembelajaran. Untuk melakukan hal tersebut guru menerapkan langkahlangkah berikut: preview (media dan bahan), prepare (teknlogi media dan bahan), persiapan lingkunagan, 
persiapan siswa, dan menyediakan pengalaman belajar.

Dalam langkah Require learner participation (mengembangkan peran serta siswa) merupakan tindak lanjut dari siswa seperti membuat latihan hasil dari pembelajaran yang terjadi. Sebelum siswa dinilai secara formal, siswa perlu dilibatkan dalam aktivitas pembelajaran seperti memecahkan masalah, simulasi, kuis atau presentasi.

Setelah

pelaksanaan

pembelajaran, yang penting dievaluasi adalah pengaruh pada belajar siswa. penilaian itu seharusnya tidak hanya menguji tingkat ketercapaian siswa pada tujuan pembelajaran, tetapi juga menguji proses pembelajaran dan pengaruh penggunaan teknologi dan media.

Sebuah media pembelajaran yang telah siap digunakan harus dinilai untuk menguji efektivitas dan dampak pembelajaran. Nilai yang dimaksud melibatkan beberapa aspek diantaranya menilai pencapaian siswa, pembelajaran yang ditampilkan, pemilihan metode dan media, kualitas media, petunjuk guru dan petunjuk siswa.

Dengan demikian dapat disimpulkan desain pembelajaran adalah praktek penyusunan media teknologi komunikasi dan isi untuk membantu agar dapat terjadi transfer pengetahuan secara efektif antara guru dan peserta didik.

Media dalam bidang pendidikan umumnya dihubungkan dengan benda-benda, alat-alat, perkakas dan bahan-bahan pendidikan dan pengajaran. Dalam penelitian pengembangan ini media yang dikembangkan adalah Media Jaringjaring Bangun Ruang untuk mata pelajaran Matematika kelas V semester 2 di Sekolah Dasar Negeri Pucang III Kecamatan Sidoarjo tahun ajaran 2010/2011.. Sehubungan dengan hal tersebut diatas maka berikut akan diuraikan tentang Media, Bangun Ruang dan Jaring-jaring Bangun Ruang.

\section{Media}

Media berasal dari bahasa Latin dan merupakan bentuk jamak dari kata "medium" yang secara harfiah berarti "perantara" yaitu perantara sumber ppesan (a source) dengan penerima pesan (a receiver).Menurut Heinich media merupakan alat saluran komunikasi.

Menurut Enright (1972:96) "media adalah ikhtiar-ikhtiar untuk memperoleh, mengolah atau menyusun kembali informasi pandang dan dengar atau gabungan informasi pandang dan dengar dengan cara grafis, Fotografik, elekronik atau cara mekanik".

\section{Bangun Ruang}

Travers $\quad \mathrm{dkk}$ (1987:98) menyatakan bahwa "Geometri is the study of the relationship between among points, lines, angels, surfaces and solids." Dengan demikian geometri adalah ilmu yang membahas tentang hubungan 
antara titik, sudut, garis, bidang dan bangun-bangun ruang. Ada dua macam geometri yang dibahas di SD yaitu geometri datar dan geometri ruang yang meliputi balok, kubus, limas, prisma, bola, tabung dan kerucut.

\section{Jaring-jaring Bangun Ruang}

Jaring -jaring adalah pembelahan sebuah bangun yang berkaitan sehingga seandainya digabungkan akan menjadi sebuah bangun ruang tertentu. "Jaringjaring bangun ruang terdiri dari beberapa bangun datar yang dirangkai. Jaring-jaring dapat dibuat dari berbagai bangun ruang. Sebuah kotak mempunyai rusuk. Rusuk-rusuk itu juga merupakan jaring-jaring. Jika sebuah kotak kita lepas perekatnya, maka akan terbentuk jaring-jaring." (Sunaryo, 2007:239).

\section{Respon Siswa}

Respon siswa adalah pendapat/penilaian siswa terhadap pelaksanaan pembelajaran. Respon siswa ini diukur dengan cara mengisi angket setelah pelaksanaan Kegiatan Pembelajaran dengan instrumen angket respon siswa. Komponen yang dimaksud meliputi: Materi pelajaran, Lembar Kerja Siswa (LKS), Media belajar, suasana pembelajaran, dan cara guru mengajar.

Penelitian ini merupakan penelitian pengembangan yang didesain dengan model Research and
Development menurut Borg and Gall.

Tahap pelaksanaan model pengembangan menurut Borg and Gall (2008:775) adalah sebagai berikut:

1. Research and information collecting (Penelitian dan mengumpulkan informasi)

2. Planning (Perencanaan)

3. Develop preliminary form of product (Mengembangkan format produk awal)

4. Preliminary field testing (Uji lapangan awal)

5. Main product revision (Revisi produk utama)

6. Main field testing ( Uji lapangan utama)

7. Operational product revision (Revisi produk operasional)

8. Operational field testing (Uji operasional lapangan)

9. Final product revision (Revisi produk akhir)

10. Dissemination and implementation (Penyebaran dan implementasi)

Penelitian dilaksanakan dalam dua tahap. Tahap pertama adalah tahap pengembangan bahan ajar, dan tahap kedua adalah tahap pengembangan pembelajaran. Dalam tahap perencanaan ini, peneliti mengadopsi unsur yang terdapat pada prosedur Kemp dkk. (1994), yaitu;

a. Instructional Problems (Analisis Tujuan), 
b. Learner Characteristics (Analisi Karakteristik Siswa),

c. Task Analysis (Analisis tugas),

d. Instructional Objectives (Tujuan pembelajaran),

e. Content Sequencing (Rangkaian isi),

f. Instructional Strategies (Strategi pembelajaran),

g. Instructional Delivery (Pemberian pembelajaran),

h. Evaluation Instrumens (alat evaluasi),

i. Instructional Resources (Sumber-sumber pembelajaran).

Dari KTSP mata pelajaran Matematika kelas V Standar kompetensi Geometri dan Pengukuran, dapat diuraikan isi materi sebagai berikut;

\section{Standar Kompetensi: 6 .}

Memahami sifat-sifat bangun datar dan bangun ruang serta hubungan antar bangun.

\section{Kompetensi}

dasar:

Menentukan jaring-jaring berbagai bangun ruang sederhana.

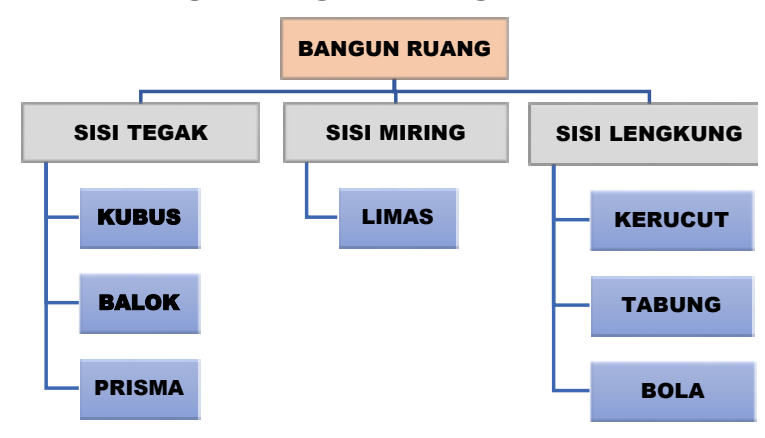

$\begin{array}{lrr}\begin{array}{c}\text { Penelitian ini } \\ \text { dikembangkan dua }\end{array} & \text { macam } \\ \text { instrumen evaluasi yaitu: } & \end{array}$

1) instrumen evaluasi untuk mengetahui kualitas proses pembelajaran dan

2) instrumen evaluasi untuk mengetahui hasil belajar.

Penelitian pengembangan merupakan proses yang memakan waktu dan mahal. Diseminasi mengacu pada proses membantu pengguna potensial menjadi sadar produk. Juga, perlu untuk menunjukkan bahwa produk diimplementasikan sesuai dengan spesifikasi pengembang sehingga menghasilkan efek yang dimaksudkan. Pelaksanaan mengacu pada proses membantu adopter dari produk untuk menggunakannya dalam cara yang dimaksudkan oleh para pengembang.

Data berupa angka rerata atau presentase yang berasal dari data angka hasil masing-masing instrumen. Data angka dijadikan data deskriptif sesuai dengan kriteria masing-masing. Instrumen yang dibuat meliputi instrumen kelayakan Rencana Pelaksanaan Pembelajaran, instrumen kesesuaian LKS, instrumen telaah media, instrumen observasi (aktivitas siswa dan aktivitas guru) dan instrumen angket untuk respon siswa.

Dalam hal ini siswa berpendapat apakah siswa merasa senang atau tidak dalam kegiatan pembelajaran, dan menyatakan bahwa 
kegiatan pembelajaran merupakan hal baru atau tidak. Respon siswa terhadap kegiatan belajar mengajar dijaring melalui Angket, yaitu Pendapat Siswa Terhadap Kegiatan Belajar Mengajar. Angket tersebut diberikan kepada siswa pada akhir kegiatan ujicoba perangkat pembelajaran. Persentase respon siswa menunjukkan bahwa mayoritas siswa menyatakan senang mengikuti pelajaran yang menyenangkan, dan yang juga penting menurut mereka adalah banya memperoleh kesempatan berbicara, mengeluarkan pendapat, atau bertanya kepada guru atau teman Berdasarkan faktor-faktor tersebut di atas, ada beberapa simpulan tertulis dari siswa berkaitan dengan respon positif.

Penelitian pengembangan merupakan proses yang memakan waktu dan mahal. Diseminasi mengacu pada proses membantu pengguna potensial menjadi sadar produk. Juga, perlu untuk menunjukkan bahwa produk diimplementasikan sesuai dengan spesifikasi pengembang sehingga menghasilkan efek yang dimaksudkan. Pelaksanaan mengacu pada proses membantu adopter dari produk untuk menggunakannya dalam cara yang dimaksudkan oleh para pengembang.

Dalam hal ini penegembang dapat mendesiminasilkan produk melalui pertemuan/ forum guru/pembelajar atau menuliskannya di jurnal.
Pengamatan dilakukan oleh empat orang pengamat seperti yang tertera pada tabel pengamatan. Sebelum melakukan pengamatan, para pengamat akan diberikan penjelasan dan latihan oleh peneliti perihal kegiatan pengamatan selama Ujicoba.

\section{DAFTAR PUSTAKA}

Arsyad, Azhar. Media Pembelajaran, Divisi Buku Perguruan Tinggi, P.T. Raja Grafindo Persada, Rajawali Press, Jakarta.

Borg Walter R. and Gall Meredith Damien. 1983. Educational Research An

Introduction. 4th. edition, Longman, New York and London. Departemen Pendidikan Nasional, 2006, BSNP Panduan

Penyusunan Kurikulum Tingkat

Satuan Pendidikan Jenjang

Pendidikan Dasar dan Menengah, Departemen Pendidikan Nasional, Jakarta.

Departemen Pendidikan Nasional, 2006, Kurikulum Sekolah Dasar (SD) Panduan Pengembangan

Rencana Pelaksanaan

Pembelajaran (RPP) Sekolah

Dasar (SD) Mata Pelajaran

Matematika. Departemen

Pendidikan Nasional, Jakarta

Departemen Pendidikan Nasional, 2006, Kurikulum Standar

Kompetensi Mata Pelajaran

Matematika Sekolah Dasar dan

Madrasah, Departemen

Pendidikan Nasional, Jakarta 
Direktorat Tenaga Kependidikan Direktorat Jenderal Peningkatan Mutu Pendidik dan Tenaga Kependidikan Departemen Pendidikan Nasional Tahun. $2007 . \quad$ Pengembangan Kepribadian.(Materi diklat pembinaan kompetensi calon kepala sekolah/kepala sekolah). Jakarta

Gagne R., Briggs L. and Wager W. 1992. Principles of Instructional Design. 4th. edition, Harcourt, Brace, Javanovich, Orlando.

Hamalik, Oemar, (1990). Strategi Belajar Mengajar Berdasarkan CBSA, Bandung, Sinar Baru.

Heinich R., Molenda M., and Russell J. (1993). Instructional Media and the New Technologies of Instruction, 4th edition, Macmillan, New York.

Hurlock, Elizabeth B. (1974). Developmental Psychology. Mc Graw-Hill

Kemp J. and Smellie D. (1989). Planning, Producing and Using Instructional Media, 6th.edition, Harper and Row, New York.

Kemp J., Harper and Row. (1985). The Instructional Design Process, New York.

Lampiran Keputusan Mentri Pendidikan Nasional RI No. 22 Tahun 2006, Tanggal 23 Mei 2006, tentang Standar Isi. Dirjen Managemen Dikdasmen, Depdiknas.
Othman Jantan. (1999). Peranan dan Cabaran Pusat Sumber Sekolah di Alaf Baru. Johor : PSPN.

Reiser R. and Gagne R. Selecting Media for Instruction, Educational Technology Publications, New Jersey.

Riduwan, (2003). Skala Pengukuran Variable Penelitian. Alfabeta, Bandung.

Riyanto, Yatim. (2001). Metodologi Penelitian Pendidikan. SIC, Surabaya.

R.M. Brown. (1990). Teknologi Pengajaran. Kuala Lumpur : Dewan Bahasa dan Pustaka.

R.M.W. Travers. (1994). Teknologi Pengajaran. Kuala Lumpur : Dewan Bahasa dan Pustaka.

Rokiah, Ismail. (1999). Bahan Pelbagai Media. Johor : PSPN.

Sharifah Alwiah Alsagoff. (1994).Teknologi Pengajaran. Kuala Lumpur : Dewan Bahasa dan Pustaka.

Schramm. (1994). Teknologi Pengajaran. Kuala Lumpur : Dewan Bahasa dan Pustaka.

Smaldino, S.E., Russell, J., Heinich, R., \& Molenda, M., (2004). Instructional technology and media for learning. $\quad\left(8^{\text {th }}\right.$ ed.). Englewood Cliffs, N.J. Prentice Hall.

Sunaryo, R.J, Matematika 5 : untuk SD/MI kelas 5. 2007. Jakarta: Pusat Perbukuan, Departemen Pendidikan Nasional,

Suryabrata, Sumadi, (1984). Psikologi Pendidikan, CV. Rajawali, Jakarta. 
Susilana, R., Riyana, C., (2008).Media Pembelajaran

Hakikat,Pengembangan,

Pemanfatan dan Penilaian, FIP UPI, Bandung.
Yusuf, Hashim. (1997). Media Pengajaran Untuk Pendidikan dan Latihan : Shah

Alam: Siri Pendidikan Fajar Bakti. 